\title{
ARTICLE OPEN \\ HELPing older people with very severe chronic obstructive pulmonary disease (HELP-COPD): mixed-method feasibility pilot randomised controlled trial of a novel intervention
}

Susan Buckingham ${ }^{1}$, Marilyn Kendall ${ }^{2}$, Susie Ferguson ${ }^{3}$, William MacNee ${ }^{3}$, Aziz Sheikh ${ }^{1}$, Patrick White ${ }^{4}$, Allison Worth ${ }^{5}$, Kirsty Boyd ${ }^{2}$, Scott A Murray ${ }^{2}$ and Hilary Pinnock ${ }^{1}$

BACKGROUND: Extending palliative care to those with advanced non-malignant disease is advocated, but the implications in specific conditions are poorly understood.

AIMS: We piloted a novel nurse-led intervention, HELPing older people with very severe chronic obstructive pulmonary disease (HELP-COPD), undertaken 4 weeks after discharge from hospital, which sought to identify and address the holistic care needs of people with severe COPD.

METHODS: This 6-month mixed-method feasibility pilot trial randomised (ratio 3:1) patients to HELP-COPD or usual care. We assessed the feasibility of using validated questionnaires as outcome measures and analysed the needs/actions recorded in the HELP-COPD records. Semi-structured interviews with a purposive sample of patients, carers and professionals explored the perceptions of HELP-COPD. Verbatim transcriptions and field notes were analysed using Normalisation Process Theory as a framework. RESULTS: We randomised 32 patients (24 to HELP-COPD); 19 completed the study (death = 3, ill-health = 4, declined =6). The HELPCOPD record noted a mean of 1.6 actions/assessment, mostly provision of information or self-help actions: only five referrals were made. Most patients were positive about HELP-COPD, discussing their concerns and coping strategies in all domains, but the questionnaires were burdensome for some patients. Adaptation to their slowly progressive disability and a strong preference to rely on family support was reflected in limited acceptance of formal services. Professionals perceived HELP-COPD as addressing an important aspect of care, although timing overlapped with discharge planning.

CONCLUSIONS: The HELP-COPD intervention was well received by patients and the concept resonated with professionals, although delivery post discharge overlapped with existing services. Integration of brief holistic care assessments in the routine primary care management of COPD may be more appropriate.

npj Primary Care Respiratory Medicine (2015) 25, 15020; doi:10.1038/npjpcrm.2015.20; published online 16 April 2015

\section{INTRODUCTION}

Extending palliative care to people with advanced non-malignant disease is widely advocated, ${ }^{1,2}$ but the implications in specific diseases are poorly understood. People with very severe chronic obstructive pulmonary disease (COPD) have a well-recognised burden of disabling physical symptoms, compounded by comorbidity, psychological distress and social isolation, ${ }^{3-5}$ although they rarely have access to co-ordinated supportive care. . $^{3,4,6}$

The current approach, predicated on an ability to recognise a terminal phase, ${ }^{7,8}$ has been challenged in the context of COPD, ${ }^{9}$ in which prognostication for individuals is unpredictable. ${ }^{10,11}$ In addition, qualitative data suggest that a 'point of transition' to palliative care is meaningless in a life-long condition characterised by a fluctuating, unpredictable decline. ${ }^{12,13}$ This is compounded by a tendency for people with COPD to be 'silent' about their physical and social disabilities. ${ }^{12,14}$ Recognising trigger events may be a strategy to overcome these professional and patient barriers. ${ }^{15}$ Analogous to 'red flags' in the context of diagnosis, triggers are events (such as hospital admissions) in the life of the disease that are meaningful to patients as signifying deterioration in their condition, and visible to health and/or social care professionals so that they can trigger holistic assessment of needs. Palliation of symptoms and supportive care can then be intensified without the requirement to identify end-stage disease.

Through a programme of work, ${ }^{16,17}$ we developed a novel intervention, HELPing older people with very severe chronic obstructive pulmonary disease (HELP-COPD), involving a proactive holistic assessment of physical, psychological, social and spiritual needs delivered by a specialist respiratory nurse shortly after an admission with an exacerbation of COPD. Our pilot trial used quantitative and qualitative methods to assess feasibility, acceptability and potential impact of the HELP-COPD intervention and to test the trial procedures.

\section{MATERIALS AND METHODS}

This 6-month feasibility pilot was conducted during 2012/13 with ethical approval from South East Scotland Research Ethics Committee (Ref:12/SS/ 0016) and governance approval from NHS Lothian (No:2012/R/RES/02).

\footnotetext{
${ }^{1}$ Allergy and Respiratory Research Group, Centre for Population Health Sciences, The University of Edinburgh, Edinburgh, UK; ${ }^{2}$ Primary Palliative Care Research Group, Centre for Population Health Sciences, The University of Edinburgh, Edinburgh, UK; ${ }^{3}$ Centre for Inflammation Research, Queen's Medical Research Institute, The University of Edinburgh, Edinburgh, UK; ${ }^{4}$ Division of Health and Social Care Research, Department of Primary Care and Public Health Sciences, King's College London, London, UK and ${ }^{5}$ Wellcome Trust Clinical Research Facility, The University of Edinburgh, Edinburgh, UK.

Correspondence: H Pinnock (hilary.pinnock@ed.ac.uk)
}

Received 4 November 2014; revised 6 January 2015; accepted 17 January 2015 
Participants and recruitment

People registered with Lothian general practices admitted to Edinburgh Royal Infirmary or St John's Hospital, Livingstone with a primary diagnosis of exacerbation of COPD were eligible. We excluded people with other significant lung disease, those unable to give informed consent (e.g., because of severe dementia) or to complete questionnaires in English. The trial respiratory nurse (SF) liaised with the ward staff to identify potentially eligible patients whom she approached with information about the study and obtained written informed consent.

\section{Questionnaires}

We assessed the feasibility in this group of patients of using a range of validated questionnaires to assess outcomes. This included the Functional Assessment of Chronic Illness Therapy with the respiratory sub-scale (Functional Assessment of Cancer Therapy-Lung) that we considered might be a suitable primary outcome measure for a future trial. ${ }^{18,19}$ Other questionnaires measured health-related quality of life ${ }^{20}$ and physical, ${ }^{21-23}$ psychological $^{24}$ and spiritual well-being. ${ }^{25}$

\section{Baseline assessment and randomisation}

The trial researcher (SB) visited the patient at home 2 weeks after discharge, undertook a baseline assessment (COPD-relevant history, smoking status, co-morbidity) and administered questionnaires, ${ }^{18-25}$ and then randomised in the ratio of 3:1 (block size 8) using a computergenerated random sequence (Health Services Research Unit, Edinburgh) to HELP-COPD or usual care.

\section{HELP-COPD intervention}

The HELP-COPD intervention is illustrated in Figure 1.

The trial respiratory nurse, experienced in palliative aspects of respiratory care, arranged a home visit approximately 4 weeks post discharge, during which she used the exemplar open questions on the HELP-COPD record (see Supplementary Information) to prompt discussion about any physical, psychological, social or spiritual concerns. A checklist of agreed actions was recorded prominently on the HELP-COPD record to facilitate implementation, and referrals made through the usual channels.

The completed one-page record was retained by the patient, with copies for the primary and secondary care records. The respiratory nurse telephoned the patient at 1,3 and 6 months to check progress with actions.
Usual care and routine clinical care

Usual care provided to people in both groups included discharge planning with appropriate community or hospital follow-up, and management in accordance with national guidelines. ${ }^{26}$

\section{Quantitative data collection}

The trial questionnaires, ${ }^{18-25}$ plus a one-page questionnaire about health care contacts, were posted to the patient at 3 months (with postal and telephone reminders), and administered by the trial researcher during a home visit at 6 months. Details of referrals to other health/social care agencies were taken from the HELP-COPD record. Data were entered onto the trial database by the trial researcher, with $10 \%$ checked for accuracy.

\section{Sample size and statistical analysis}

No formal sample size calculation was undertaken for this pilot work. We aimed to recruit 40 patients (randomised 30 to HELP-COPD: 10 to usual care), this being sufficient to assess feasibility of the intervention and trial procedures. In keeping with standard practice, we did not undertake any formal statistical comparisons to avoid over-interpretation of this small data set.

\section{Qualitative data collection}

We purposively sampled up to 10 participants from the HELP-COPD group with diverse demography, co-morbidity and family/social circumstances, and scheduled interviews with them (and a carer, if preferred) at three time points:

- Shortly after the HELP-COPD assessment to capture reflections on the experience.

- After 6 weeks to explore whether actions were being implemented.

- After 6 months, to explore any benefit/detriment of using HELP-COPD, whether any actions were outstanding and why.

We recruited professionals from social work, primary care and community physiotherapy or nursing teams involved in providing care to people with COPD, and adopted flexible strategies to enable participation (e.g., individual interviews, telephone options, focused discussions at team meetings). The aim was to explore perceptions of the benefits (or otherwise) of the intervention. The topic guide (see Supplementary Information) was informed by the constructs of the Normalisation Process Theory (NPT), ${ }^{27}$ (summarised in Table 1) and refined iteratively as themes emerged. Interviews were audio-recorded with participants' written consent.

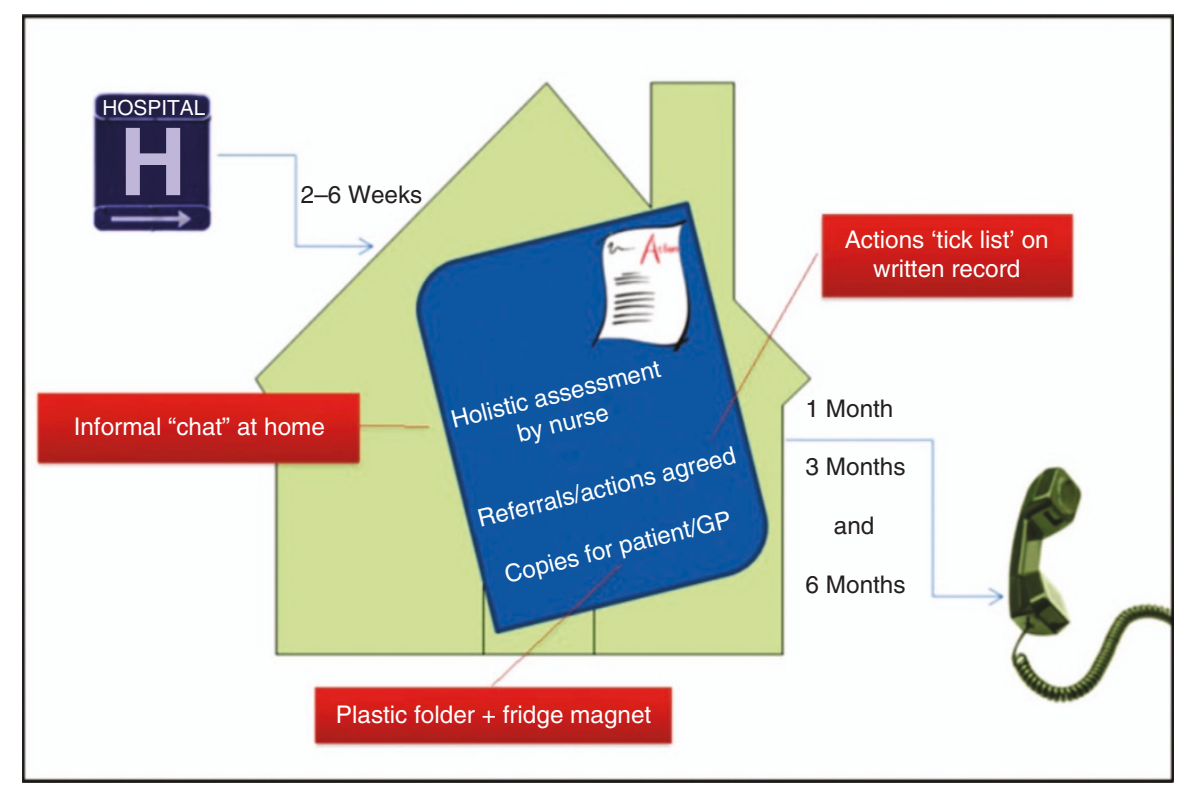

Figure 1. The HELP-COPD intervention. GP, general practitioner; HELP-COPD, HELPing older people with very severe chronic obstructive pulmonary disease. 
Table 1. Normalisation Process Theory (NPT) ${ }^{27}$

\begin{tabular}{ll}
\hline Construct & Description \\
\hline Coherence & 'Sense-making' How is the intervention understood by participants? How do they compare it with other prac \\
Cognitive participation & How do participants come to take part in a practice? What keeps them motivated to continue taking part? \\
Collective action & How do participants make it work? How are their activities organised and structured? \\
Reflexive monitoring & How do participants evaluate a practice? How does this change over time and what are its effects?
\end{tabular}

NPT challenges researchers to consider how their novel intervention might become 'normalised' (or not) in routine practice.

\section{Additional data sources}

The respiratory nurse made field notes immediately after each HELP-COPD contact (initial face-to-face visit, and then telephone follow-up calls at 1, 3 and 6 months (see Figure 1)), and was interviewed twice: at the beginning and towards the end of the study. Copies of completed HELP-COPD records provided documentary evidence.

\section{Analysis}

The fully transcribed interviews were coded by the qualitative researcher (MK) using NVivo. We used NPT, highlighted as potentially relevant during the theoretical modelling phases of our programme of work, ${ }^{16}$ as a framework for our analysis ${ }^{27}$ (see Table 1). At the end of the study, the trial team (HP, MK, SB, SF and Cristina Matthews) used the online NPT toolkit ${ }^{28}$ to aid understanding of the experience of using HELP-COPD as reflected in our data.

Interpretation and synthesis of qualitative and quantitative data Members of the team (MK, SB, SF and Cristina Matthews) met on multiple occasions to construct in-depth case studies of participants for whom we had quantitative, qualitative and documentary data, as well as field notes from the researchers and respiratory nurse. For each individual, we noted any 'unmet' needs, 'recently met' needs (e.g., referrals made during discharge planning), evidence of any impact (or not) of the HELP-COPD intervention and noted any relevant context that may have affected the outcome. Individual cases were then compared and contrasted to aid understanding of the feasibility and impact of the intervention.

As findings emerged, we arranged discussions with the NHS Lothian Respiratory Managed Clinical Network (Managed Clinical Networks are multidisciplinary, cross-sector groups that oversee provision of clinical services throughout Scotland) and palliative care colleagues. ${ }^{29}$ Preliminary findings were discussed in a workshop (including grant holders, invited clinicians and researchers), enabling us to site our intervention in the context of existing services. We also presented the findings to our Lay Advisory Group and gained their perspective.

Finally, we used both qualitative and quantitative data to answer our predefined key questions (see Table 2), which addressed feasibility of the intervention and the trial processes.

\section{RESULTS}

Flow of patients through the trial

See Figure 2 for the CONSORT diagram, and Table 2 (Question 9) for further details. We had substantial attrition largely owing to illhealth/death. Of the 44 patients who provided consent during their admission, we randomised 32 patients after their baseline assessment 2 weeks post discharge. In all, 23 of the 24 allocated to HELP-COPD were well enough to participate in the intervention at 4 weeks. Further attrition meant that 19 participants completed the follow-up questionnaires.

Recruitment to the qualitative study

Eight patients (three with carers) provided 12 interviews. In addition, we collected data from 28 social or health care professionals in 18 individual interviews and two group interviews.
Baseline characteristics

Baseline characteristics are given in Table 3. The HELP-COPD group had more co-morbid conditions and more previous hospital admissions than the usual care group.

Feasibility of the intervention

Table 2 (Questions 1-6) gives the answers to our questions about the feasibility of the intervention and the implications for future practice. In summary, the HELP-COPD intervention was well received by patients, and the concept resonated with professionals, but we identified fewer actions than anticipated (an average of 1.6 actions/assessment, of which five were referrals: most were provision of information or contact details of support agencies (see Table 4 for further details)). Key reasons for this were the overlap with existing discharge planning, patients' adaptation to their long-term disability and their over-riding preference to retain independence.

\section{Feasibility of the trial processes}

Table 2 (Questions 7-14) gives the answers to our questions about the feasibility of the trial processes and the implications for future research. Questionnaire completion proved burdensome for some patients, with seven declining to complete follow-up questionnaires citing ill-health. See Supplementary Information for a table of quantitative outcomes.

Using NPT to explore why the intervention appeared not to be as successful as hoped and to inform future iterations

The NPT scoring was informed by the qualitative data, the minutes of seven steering group meetings and eight Lay Advisory Group meetings, and feedback from discussions with NHS Lothian Managed Clinical Network and the secondary care palliative care team. (See Supplementary Data for the spider plots derived from the NPT toolkit.)

\section{Coherence: meaning and sense-making by participants}

The patients spoke positively when asked about their HELP-COPD assessment, although their descriptions were often interspersed with stories about other professionals whom they had seen, and thus it was not always clear how distinct the intervention was. Some described the novelty of such a comprehensive assessment:

'I've never had anything like this before. Not in-depth. You get asked basic questions [at the surgery]' [T001]

Individuals highlighted specific benefits that had followed from the discussion about spiritual or psychological needs.

'Yes, I think, possibly one thing came out of it on the psychological side. It asks 'Do you often feel anxious or panicky?' In general I would have said 'no', but I suddenly realised that 'Yes, I do when I get breathless' ... I hadn't really thought about that 
Table 2. Answers to the a priori key questions for the feasibility pilot and implications for future development

\begin{tabular}{ll}
\hline Question & Result \\
\hline $\begin{array}{l}\text { Feasibility of the intervention } \\
\text { 1. How acceptable }\end{array}$ & $\begin{array}{l}\text { Patients were generally positive about the assessment, openly discussing } \\
\text { is the }\end{array}$ \\
$\begin{array}{l}\text { intervention? } \\
\text { concerns and coping strategies in all domains. Professionals were } \\
\text { interested in the concept of HELP-COPD and considered that the } \\
\text { intervention was feasible but, noted some practical issues (e.g., overlap } \\
\text { with discharge planning and communication with GPs) }\end{array}$
\end{tabular}

Implication for future iterations

2. In what proportion of patients was an action identified?

3. What actions were identified/ triggered by the HELP-COPD assessment?

4. Did follow-up help ensure that referrals occurred in a timely

manner?

\section{What are the} barriers to implementation of actions?

6. How may the intervention be improved?
Twenty-three patients received the intervention. Overall, 37 action points were noted: an average of 1.6 per assessment. Of these:

- Five were referrals (one each to pulmonary rehabilitation, the home oxygen service, carer support, social care direct and a request to the GP).

- Fifteen were contacts for the patient to follow-up (e.g., social support agencies)

- Seventeen people were given information about COPD, and local services.

- Physical symptoms were discussed in 21 assessments, but only one required action (referral to GP about morphine to relieve breathless)

- Psychological issues were discussed in 19 assessments, but no actions were generated. Most felt well supported by their family.

- A range of social issues were discussed in most assessments, but only one referral (for help with social care). Maintaining independence was the priority.

- Fifteen spoke of pleasure in family life and/or the importance of their faith. Five had put their affairs in order recognising 'We all have to die sometime'.

The follow-up telephone calls generated few actions and were perceived as achieving very little. In contrast, clinicians from community teams highlighted on-going care as important for identifying problems.

Offers of help were declined for a number of reasons:

- Over-riding preference for independence (often with family support)

- 'I don't want other people to do it if you can do it yourself...it would need to be bad, you know, that I couldn't cope' [Pause] 'I get there' [laughs] [T042]

- Previous bad experience of social services

- 'I mean, 5 years ago, the trouble I had with the benefits, I thought well I've got emphysema. Or are they right? Am I just imagining this?' [T044]

- Services perceived as inappropriate, inaccessible and/or unavailable

The intervention did not seem to work quite as intended: suggestions for future included:

- An on-going relationship may facilitate detection of need

- Avoid duplication of services

- Detecting problems and offering help at an earlier stage in the disease process may be better
The core concept was acceptable, but communication/integration with other services needs further consideration

The reasons for fewer actions than anticipated needs to be explored and addressed. Key issues were: overlap with discharge planning, the
priority attached to retaining independence
and adaptation to long-term disability.
priority attached to retaining independence

Although few actions were generated, the physical, psychological, social and spiritual aspects of the assessment resonated with the participants and should be retained as the underpinning structure of the assessment. 
Table 2. (Continued)

\begin{tabular}{|c|c|}
\hline Question & Result \\
\hline $\begin{array}{l}\text { 9. What is the likely } \\
\text { attrition rate? }\end{array}$ & $\begin{array}{l}\text { Forty-four patients provided consent during their admission: } \\
\text { - Twelve were unable to participate in the baseline assessment } 2 \text { weeks } \\
\text { post discharge because of death }(n=3) \text {, readmission }(n=3) \text {, too ill } \\
(n=3) \text {, uncontactable }(n=3) \text {. } \\
\text { - We randomised } 32 \text { patients. Twenty-four were allocated to the HELP- } \\
\text { COPD intervention: one was too ill to participate in the intervention at } \\
4 \text { weeks. } \\
\text { - On-going attrition throughout the } 6 \text { months: } 7 \text { of } 23 \text { participants in the } \\
\text { HELP-COPD group and five of eight in the usual care group mostly for } \\
\text { reasons of ill-health. }\end{array}$ \\
\hline
\end{tabular}

10. What is the Documentary evidence from the HELP-COPD records suggested that most appropriate referrals to or uptake of pulmonary rehabilitation (one of the actions we duration for a trial? identified) or other referral agencies (oxygen, social services) take time to implement.

\section{How feasible/ Questionnaire completion proved burdensome for some patients,} practical are the with 13 unable/declining to complete follow-up questionnaires proposed outcome (3 had died, 3 were too ill, 2 had family illness/bereavement, 4 gave no measures? specific reason). For those well enough to complete the questionnaire, FACT-L (the outcome we were considering as a future primary outcome) appeared to be acceptable.

\section{What is the expected change in the primary} outcome measure? important difference of 5.5

\section{The FACT-L showed a trend to a difference at 6 months (See}

Supplementary Information). The change from baseline (85 to 97) in the intervention group is substantial and at least twice the minimum clinically

\section{Which}

outcomes matter to patients/carers?

The Lay Advisory Group considered that important outcomes for them were greater independence, ability to improve their social lives and to live to use it.

14. What is

'usual care'?
Usual care in the context of the HELP-COPD intervention is (i) discharge planning and (ii) community services designed to help prevent admissions.
Implication for future iterations

This very substantial attrition, mainly related to severity of disease and the fact that we were recruiting at a time when the disease had just exacerbated, is an important consideration for researchers recruiting people with COPD at the time of an admission.

Our experience suggests that an RCT should be at least 6 months in duration.

In this frail group of patients use of questionnaires needs to be rationalised. FACT-L covers all domains and obviates the need for multiple questionnaires.

The substantial attrition means that numbers were very small, and difficult to interpret with confidence

FACT-L reflects this and endorses our decision

Future iterations of HELP-COPD need to integrate, not overlap, with these services.

Abbreviations: FACT-L, Functional Assessment of Cancer Therapy-Lung; GP, general practitioner; HELP-COPD, HELPing older people with very severe chronic obstructive pulmonary disease; RCT, randomised controlled trial.

before, so I could put that down and we could actually address that.' [R005]

There was a strong sense from professionals that existing services did not address the complex and long-term supportive care needs of people with severe COPD. The uncertain prognosis meant that palliative care services-inextricably linked in the minds of both professionals and patients to the final months of life -were not always seen as appropriate.

'I go to the [palliative care] services almost cap in hand and again ... the first question they'll ask me is 'Do you think they're likely to die within 3 months?' I don't know' [TProf03: Community nurse]

'Patients don't understand palliative care, they still think it's for cancer patients... ... they think that if they're referred to the hospice they're going in there to die ...' [TProf01: Community respiratory physiotherapist]

The HELP-COPD intervention was perceived as potentially providing something distinct to current services, and delivery 'closer to home' was considered to be 'much less daunting'. However, the timing of the assessment meant that actions overlapped with the step-up in care that followed an admission.

A general practitioner observed that the HELP-COPD summary could be useful for colleagues less familiar with the patient than he was, but highlighted how the record could easily be overlooked in the electronic health record.
'Let me see if there's a coding thing 'action plan' anywhere, [looking and reading from screen] ... [speaking to researcher again] so I guess that the first bit of feedback is that nobody would know there was a [HELP-COPD] action plan' [GP004]

Cognitive participation: commitment and engagement by participants

HELP-COPD was delivered by the trial research nurse, and thus it did not involve NHS employees undertaking any new roles. However, professional buy-in to the concept of providing supportive care for people with severe COPD was evident. Members of the community teams described having attended 'introduction to palliative care' courses or perceived their role to include advanced care planning.

I would say, even in the last, probably, week, I've spoken to at least two patients around palliative care sort of end-of-life issues to include, sort of, resuscitation, or just issues around that that' [TProf01: Community respiratory physiotherapist]

The Lay Advisory Group was very positive about the intervention and supportive of patients holding their own HELP-COPD record.

Collective action: the work participants do to make the intervention function

Because HELP-COPD was delivered as a research project, no specific actions were expected from NHS personnel. The 


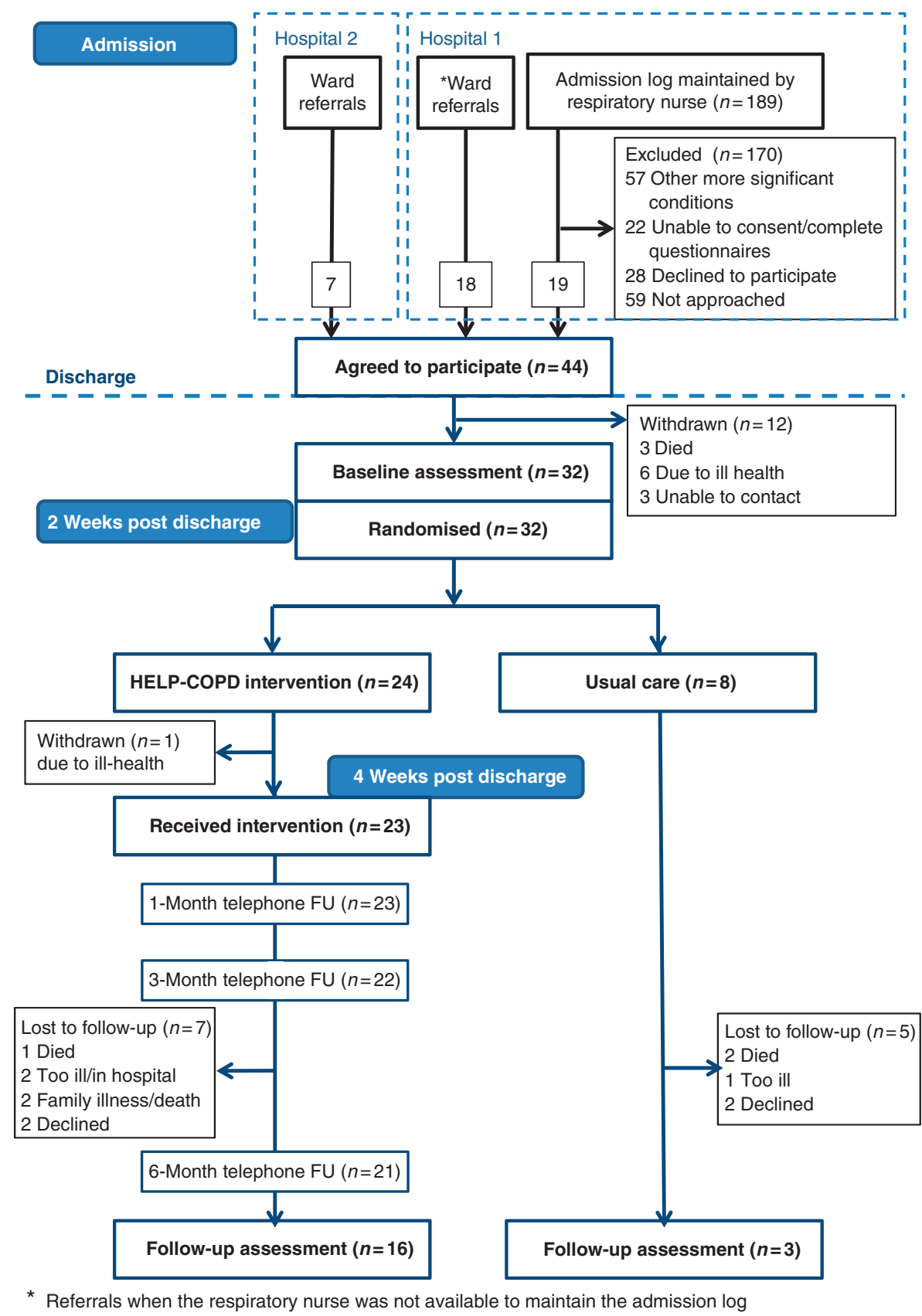

Figure 2. Flow of patients through the trial. FU, follow-up; HELP-COPD, HELPing older people with very severe chronic obstructive pulmonary disease.

participating hospitals supported identification of eligible patients and staff members participated in the workshops, suggesting active engagement (albeit to the research rather than a service).

Most patients were able to find their HELP-COPD record to show the qualitative researcher, and some explained that they had shared it with a partner or carer, although it was not clear whether this had facilitated any action(s).

'Well, [daughter] had a look at it and [son]. I have a son stays in the village as well and he had a look at it as well.' [T002]

Reflexive monitoring: participants reflect on or appraise the intervention

There was a sense that the intervention was not working quite as intended, and professionals suggested how it might be improved.
The lack of an on-going relationship between the patient and professional was seen as a disadvantage.

'... giving someone ten, fifteen, twenty minutes, half an hour as a one-off is often not the way in which to address these sort of more complex patient problems that these patients present with, which is possibly why they've come up with nothing' [Community respiratory physiotherapist]

The lack of 'actions' initially frustrated the respiratory nurse, although later she recognised that providing information about COPD was enabling people to feel more in control. The Lay Advisory Group reinforced the importance of information and education.

In general, professionals were interested in the outcomes of the study. We were, for example, invited to lead a discussion 
Table 3. Baseline characteristics

\begin{tabular}{lccc}
\hline & HELP-COPD $(\mathrm{n}=24)$ & Usual care $(\mathrm{n}=8)$ & Qualitative subgroup $(\mathrm{n}=8)$ \\
\hline Mean age (years (s.d.)) & $72.2(8.2)$ & $64.4(7.6)$ & $69.1(7.9)$ \\
Gender (\% male) & 47.8 & 50.0 & 62.5 \\
Smoking (pack-years (s.d.)) & $51.6(22.1)$ & $47.9(26.5)$ & $53.6(21.6)$ \\
Co-morbid conditions reported (mean (s.d.)) & $2.8(1.14)$ & $0.8(0.8)$ & $2.1(1.1)$ \\
Previous admissions (mean (s.d.)) & $6.8(7.2)$ & $3.1(1.8)$ & $7.6(9.9)$ \\
& & & $(n=8)$ \\
Questionnaire responses (mean (s.d.)) & $(n=23)$ & $84(10.0)$ & $82(15.4)$ \\
FACT-L & $85(21.6)$ & $70.2(10.5)$ & $73.9(11.4)$ \\
SGRQ & $69.5(16.5)$ & $4.0(0.9)$ & $4.0(0.8)$ \\
MRC dyspnoea score & $4.0(1.0)$ & $25(5.7)$ & $25.9(4.8)$ \\
COPD assessment tool & $24(7.6)$ & $8.0(4.0)$ & $7.5(1.6)$ \\
HADS- anxiety & $7.0(4.5)$ & $7.0(2.6)$ & $7.6(2.5)$ \\
HADS-depression & $7.0(3.5)$ & $28(8.9)$ & $33(7.3)$ \\
FACIT-Sp & $33(7.5)$ & & \\
\hline
\end{tabular}

Abbreviations: HELP-COPD, HELPing older people with very severe chronic obstructive pulmonary disease; FACIT-Sp, Functional Assessment of Chronic Illness Therapy-Spiritual; FACT-L, Functional Assessment of Cancer Therapy-Lung; HADS, Hospital Anxiety and Depression Scale; MRC, Medical Research Council; SGRQ, St George's Respiratory Questionnaire.

Table 4. Needs and actions resulting from the HELP-COPD assessment

\begin{tabular}{|c|c|c|}
\hline Physical & $\begin{array}{l}\text { Troublesome symptoms: breathlessness ( } n=14) \text {, fatigue or } \\
\text { weakness }(n=8) \text {, pain }(n=6) \text {, recurrent chest infections }(n=4) \text {, } \\
\text { coughing/sputum production }(n=3) \text {, weight loss }(n=3) \text {. } \\
\text { Concerns about medication }\end{array}$ & $\begin{array}{l}\text { Referrals to GP to discuss the use of morphine for } \\
\text { breathlessness }(n=1) \text {, pulmonary rehabilitation }(n=1) \text {, home } \\
\text { oxygen services }(n=1) \\
\text { Self-management plan arranged }(n=2) \text { rescue medication } \\
\text { supplied }(n=1) \text {. } \\
\text { Check the progress of pulmonary rehabilitation referral }\end{array}$ \\
\hline Psychological & $\begin{array}{l}\text { Struggling with anxiety }(n=7) \text { : Discussion of coping strategies } \\
(n=6) \\
\text { Frustration at their limitations }(n=7) \\
\text { No one described themselves as 'depressed' }\end{array}$ & $\begin{array}{l}\text { No actions were generated, as no one requested or accepted } \\
\text { help for anxiety and/or depression }\end{array}$ \\
\hline Social & $\begin{array}{l}\text { Topics covered included loneliness, bereavement, activities of daily } \\
\text { living (ADL), shopping, bathing, housework, housing, going out, } \\
\text { going on holiday. } \\
\text { Coping strategies discussed: pacing, accepting family help: a few } \\
\text { had formal carers }\end{array}$ & $\begin{array}{l}\text { Referral for help with personal care }(n=1) \text {, carer support } \\
\text { services }(n=1) \text {, assessment for a shower unit }(n=1) \\
\text { Provision of the HELP-COPD leaflet of local services and } \\
\text { voluntary agencies that could provide a range of support } \\
(n=12) \text {. } \\
\text { Provision of information about specific issues (such as going } \\
\text { on holiday, arranging insurance, volunteer drivers) was also } \\
\text { provided. }\end{array}$ \\
\hline Spiritual & $\begin{array}{l}\text { Discussion of the importance of family life and family support } \\
(n=15) \\
\text { Most of them had no worries }(n=15)\end{array}$ & No actions \\
\hline
\end{tabular}

with the Lothian Respiratory Managed Clinical Network who suggested that we should consider intervening earlier in the course of the disease, so that needs could be addressed when people were still relatively active. The Lay Advisory Group supported this approach.

\section{DISCUSSION}

\section{Main findings}

We recruited 44 patients, but had very substantial attrition, mainly related to severity of disease and because we were recruiting at a high-risk time (during an admission). On average, 1.6 actions were identified per assessment: most were providing information about resources. Trial data collection was feasible, although ill-health meant that questionnaire completion was burdensome for some patients.
Despite the few actions, patients were generally positive about HELP-COPD, and professionals perceived HELP-COPD as addressing an important aspect of care, although the post-admission timing of the intervention resulted in overlap with existing discharge planning.

Strengths and limitations of this study

Our study built on extensive qualitative work, ${ }^{12}$ a review of existing interventions ${ }^{17}$ and adopted a systematic approach to designing and piloting a complex intervention. ${ }^{16}$

The findings of our single-centre study may not be representative of other contexts. Specifically, the majority of patients were recruited from a tertiary centre with a reputation for innovative care of people with severe COPD, although participants recruited from the other Lothian hospital had a similar profile of needs/ actions. 
The substantial attrition between recruitment (during the admission) and delivery of the intervention at home 4 weeks later would have been a major issue in a fully powered randomised controlled trial. We achieved data saturation with respect to our key qualitative objective of understanding the feasibility of the intervention.

Researchers' attitudes influence design, data collection and analysis of qualitative studies; discussion with our multidisciplinary professional team and lay advisors ensured a balanced interpretation of the data. ${ }^{30}$

Interpretation of findings in relation to previously published work There has been a widespread assumption that supportive care for people with organ failure should be modelled on the successful cancer model, ${ }^{1,2,7}$ predicated on identifying people who have reached a transition point in their disease trajectory when they would benefit from a supportive care approach. ${ }^{8,31}$ However, qualitative work has questioned the relevance of such a 'transition' in $\mathrm{COPD}_{1}^{5,12}$ and has suggested that the concept of 'triggers' might be more appropriate. ${ }^{12}$ The HELP-COPD initiative used hospital admissions as a trigger, and although this had face validity there were two over-arching reasons why it seemed less successful than we had hoped.

First, the HELP-COPD intervention, in part, duplicated care already provided as part of discharge planning. Care for physical needs had already been stepped up and assessment undertaken for social support needs. Outstanding actions detected by HELPCOPD were then limited to providing information about local (often voluntary) support agencies.

Second, offers of help were frequently declined. The HELPCOPD intervention occurred 4 weeks post discharge, at a time when many people felt they were returning to (their) normal, ${ }^{5,12,14}$ and potentially needing less rather than more help. Recalibration of expectations as a result of adaptation to their slowly progressive disability ${ }^{32}$ meant that action was not necessarily wanted despite significant symptoms and social burden. In addition, an over-riding preference to cope independently meant that family help was more acceptable than outside services. ${ }^{33}$

Implications for future research, policy and practice

Despite adopting an overtly holistic approach with systematic assessment of physical, psychological, social and spiritual needs, HELP-COPD had limited success in identifying actions. The intervention thus requires further developmental work before progressing to a large-scale randomised controlled trial. ${ }^{16}$ Future iterations of HELP-COPD should retain the holistic approach, but may seek to integrate brief assessments into the annual reviews of people with symptomatic COPD, ${ }^{34}$ thus intervening earlier in the course of the disease. The burden imposed on family carers as patients eschew formal support needs to be considered and addressed.

\section{Conclusions}

The HELP-COPD intervention was well received by patients and the concept resonated with professionals, but the holistic assessment delivered 4 weeks after an admission generated few actions apart from provision of information. A more appropriate approach may be to provide holistic care routinely throughout the life-long course of the disease as an integral component of good primary care management of a long-term condition.

\section{ACKNOWLEDGEMENTS}

The authors acknowledge the invaluable help of Cristina Matthews, the project administrator, and are grateful for the support of the staff of the respiratory ward at the Royal Infirmary Edinburgh and Dr Donald Noble and Sr Kim Bracher from the respiratory team at St John's Hospital, Livingstone who helped with recruitment. Colleagues from the NHS Lothian Respiratory Managed Clinical Network, the Marie Curie Hospice, the Edinburgh Community Respiratory Team, the East and Midlothian Anticipatory Care Service and IMPACT team contributed their expertise to our discussions. The authors thank Jenny Holmes from the TeleScot team, Andy Deans, research nurse from the Royal Infirmary Edinburgh, Dumfries User Group and Tracy Finch from University of Newcastle for their contributions to the project. The Edinburgh Health Services Research Unit provided the randomisation service. The Lay Advisory Group, based in Dundee, Tayside, met eight times to guide the development of the intervention from their perspective as people with COPD. The members were Jim Anderson, Cathy Bury, Gerry Clark, Charles Ireland, Leonard Jamieson, Doris McLury, Evelyn Murray, Sheila Smith, George Smith, Jane Summers, Fred Whitnall, Ian Wylie and Rena Wallace.

\section{CONTRIBUTIONS}

HP initiated the idea for the study and led the development of the protocol, securing of funding, study administration, data analysis, interpretation of results and writing of the paper. SB and MK undertook the data collection and undertook the data analysis. SF recruited patients, delivered the intervention and contributed to understanding of the data. All the authors had full access to all the data and were involved in interpretation of the data. SB and HP wrote the initial draft of the paper, to which all the authors contributed. HP is the study guarantor.

\section{COMPETING INTERESTS}

AS is the Joint Editor-in-Chief of, and HP is an Associate Editor of, npj Primary Care Respiratory Medicine; neither were involved in the editorial review of, nor the decision to publish, this article. The authors declare no conflict of interest.

\section{FUNDING}

The Dunhill Medical Trust (grant ref: R210/0711).

\section{REFERENCES}

1 House of Commons Health Committee. Palliative Care. The Stationery Office: London, UK, 2004.

2 World Health Organization Europe. The Solid Facts: Palliative Care. World Health Organization: Copenhagen, Denmark, 2004.

3 Gore JM, Brophy CJ, Greenstone MA. How well do we care for patients with end stage chronic obstructive pulmonary disease (COPD)? A comparison of palliative care and quality of life in COPD and lung cancer. Thorax 2000; 55: 1000-1006.

4 Habraken JM, Willems DL, de Kort SJ, Bindels PJE. Health care needs in end-stage COPD: a structured literature review. Patient Educ Couns 2007; 68: 121-130.

5 Giacomini M, DeJean D, Simeonov D, Smith A. Experiences of living and dying with COPD: a systematic review and synthesis of the qualitative empirical literature. Ont Health Technol Assess Ser 2012; 12: 1-47.

6 Epiphaniou E, Shipman C, Harding R, Mason B, Murray SA, Higginson IJ et al. Coordination of end-of-life care for patients with lung cancer and those with advanced COPD: are there transferable lessons? A longitudinal qualitative study. Prim Care Respir J 2014; 23: 46-51.

7 Centers for Medicare \& Medicaid Services. Publication No. 02154: A Special Way of Caring for People Who Are Terminally III. Department of Health and Human Services: Baltimore, MD, USA, 2008.

8 The Gold Standards Framework. Available from http://www.goldstandardsframe work.org.uk (accessed October 2014).

9 Kendall M, Buckingham S, Ferguson S, Hewitt N, Pinnock H. We need to stop looking for something that is not there... NPJ Prim Care Respir Med 2014; 24: 14031.

10 Coventry PA, Grande GE, Richards DA, Todd CJ. Prediction of appropriate timing of palliative care for older adults with non-malignant life-threatening disease: a systematic review. Age Ageing 2005; 34: 218-227.

11 Christakis NA, Escarce JJ. Survival of Medicare patients after enrollment in hospice programs. N Engl J Med 1996; 335: 172-178.

12 Pinnock $H$, Kendall $M$, Murray SA, Worth A, Levack $P$, Porter $M$ et al. Living and dying with severe chronic obstructive pulmonary disease: multi-perspective longitudinal qualitative study. BMJ 2011; 342: d142.

13 Murray SA, Boyd K, Sheikh A. Palliative care in chronic illness. We need to move from prognostic paralysis to active total care. BMJ 2005; 330: 611-612.

14 Habraken JM, Pols J, Bindels PJE, Willems DL. The silence of patients with endstage COPD: a qualitative study. Br J Gen Pract 2008; 58: 844-849. 
15 Cawley D, Billings J, Oliver D, Kendall M, Pinnock H. Potential triggers for the holistic assessment of people with severe chronic obstructive pulmonary disease: analysis of multi-perspective, serial qualitative interviews. BMJ Support Palliat Care 2014; 4: 152-160.

16 Craig P, Dieppe P, Macinture S, Michie S, Nazareth I, Petticrew M. Developing and Evaluating Complex Interventions: New Guidance. Medical Research Council: London, UK, 2008.

17 Nurmatov U, Buckingham S, Kendall M, Murray SA, White P, Sheikh A et al. Effectiveness of holistic interventions for people with severe chronic obstructive pulmonary disease: systematic review of controlled clinical trials. PLoS One 2012; 7: e46433.

18 Webster K, Cella D, Yost K. The Functional Assessment of Chronic Illness Therapy (FACIT) Measurement System: properties, applications, and interpretation. Health Qual Life Outcomes 2003; 1: 79.

19 Cella DF, Bonomi AE, Lloyd SR, Tulsky DS, Kaplan E, Bonomi P. Reliability and validity of the Functional Assessment of Cancer Therapy_Lung (FACT-L) quality of life instrument. Lung Cancer 1995; 12: 199-220.

20 Jones PW, Quirk FH, Baveystock CM, Littlejohns P. A self-complete measure for chronic airflow limitation-the St George's Respiratory Questionnaire. Am Rev Respir Dis 1992; 145: 1321-1327.

21 Fletcher CM, Elmes PC, Fairbairn AS, Wood CH. The significance of respiratory symptoms and the diagnosis of chronic bronchitis in a working population. $B M J$ 1959; 2: 257-266.

22 Jones P, Harding G, Berry P, Wiklund I, Leidy NK. Improving the process and outcome of care in COPD: development of a standardised assessment tool. Prim Care Respir J 2009; 18: 208-215.

23 Jones P, Harding G, Wiklund I, Berry P, Chen W-H, Leidy N. Development and first validation of the COPD Assessment Test. Eur Respir J 2009; 34: 648-654.

24 Zigmund AS, Snaith RP. The hospital anxiety and depression scale. Acta Psychiatr Scand 1983; 67: 361-370.

25 Peterman AH, Fitchett G, Brady MJ, Hernandez L, Cella D. Measuring spiritual wellbeing in people with cancer: The functional assessment of chronic illness therapy —spiritual well-being scale (FACIT-Sp). Ann Behav Med 2002; 24: 49-58.
26 National Institute for Health and Clinical Excellence. National clinical guideline on management of chronic obstructive pulmonary disease in adults in primary and secondary care. Thorax 2004; 59: S1-S232.

27 May C. A rational model for assessing and evaluating complex interventions in health care. BMC Health Serv Res 2006; 6: 86.

28 May C, Murray E, Finch T, Mair F, Treweek S, Ballini L et al. Normalization Process Theory On-line Users' Manual and Toolkit. 2010. Available from http://www. normalizationprocess.org (Accessed October 2014).

29 University of Edinburgh. NHS Lothian Supportive and Palliative Care Indicators Tool (SPICT TM). Available from http://www.spict.org.uk (Accessed October 2014).

30 Malterud K. Qualitative research: standards, challenges and guidelines. Lancet 2001; 358: 483-488.

31 Dying Matters. Find Your 1\%: supporting GPs in delivering quality end of life care. Available from http://www.dyingmatters.org/gp.

32 Sprangers MA, Schwartz CE. Integrating response shift into health-related quality of life research: a theoretical model. Soc Sci Med 1999; 48: 1507-1515.

33 Mason B, Nanton V, Epiphaniou E, Murray SA, Donaldson A, Shipman C et al. My body's falling apart.' Understanding the experiences of patients with advanced multimorbidity to improve care: serial interviews with patients and carer. $B M J$ Support Palliat Care 2014; e-pub ahead of print, http://spcare.bmj.com/content/ early/2014/05/28/bmjspcare-2013-000639.abstract, doi: 10.1136/bmjspcare-2013000639.

34 Johnson M, Fallon M. Just good care? The palliative care of those with nonmalignant disease. Palliat Med 2013; 27: 803-804.

(i) (1) This work is licensed under a Creative Commons AttributionBY NC SA NonCommercial-ShareAlike 4.0 International License. The images or other third party material in this article are included in the article's Creative Commons license, unless indicated otherwise in the credit line; if the material is not included under the Creative Commons license, users will need to obtain permission from the license holder to reproduce the material. To view a copy of this license, visit http:// creativecommons.org/licenses/by-nc-sa/4.0/

Supplementary Information accompanies the paper on the npj Primary Care Respiratory Medicine website (http://www.nature.com/npjpcrm) 